\title{
Study on Patch Bonding for Recovery of Damaged Carbon Fiber Reinforced Thermoplastics by Four-Point Bending Method
}

\author{
Kiyotaka Obunai ${ }^{1}$, Tadao Fukuta ${ }^{1}$, Koichi Ozaki ${ }^{1}$, Rei Yamagishi ${ }^{2}$ \& Masahiro Yamamoto ${ }^{2}$ \\ ${ }^{1}$ Faculty of Computer Scienece and System Engineering, Okayama Prefectural University, Soja, Japan \\ ${ }^{2}$ Department of Systems Engineering, Graduate School of Okayama Prefectural University, Soja, Japan \\ Correspondence: Kiyotaka Obunai, Faculty of Computer Scienece and System Engineering, Okayama \\ Prefectural University, Soja 719-1197, Japan. Tel: 81-866-94-9118. E-mail: obunai@cse.oka-pu.ac.jp
}

Received: April 2, 2013 Accepted: May 2, 2012 Online Published: May 23, 2013

doi:10.5539/jmsr.v2n3p60

URL: http://dx.doi.org/10.5539/jmsr.v2n3p60

\begin{abstract}
The purpose of this study is to investigate the fracture behavior and repairability of carbon fiber reinforced thermoplastics (CFRTP). At first, four-point bending tests were conducted to characterize the bending characteristics of fabricated CFRTP. The test results show that local delamination first appeared when the applied bending strain was $2.0 \%$. When the bending strain reached $2.5 \%$, the failure of the fiber due to local buckling was observed at the compression side of the specimen. Secondly, the effect of patch bonding on the bending strength and flexural modulus was also evaluated. Test results showed that damaged specimen could be repaired by bonding of an appropriate patch layer. Patch bonding at the compression side was more effective than at the tension side. The flexural modulus of a repaired specimen was estimated by the laminate beam model.
\end{abstract}

Keywords: CFRTP, patch bonding, fracture morphology, four point bending, laminate beam model

\section{Introduction}

A carbon fiber reinforced thermoplastics (CFRTP) is known as an excellent composite material because of its high strength along with low density as well as its high productivity (Shinohara et al., 2012; Tanaka et al., 2012) and recyclability (Matsusaka et al., 2005; Suzuki et al., 2005). It is expected that CFRTP will be applied not only to racing cars but also to commercial vehicles (Goto et al., 2011). When considering commercial applications, CFRTP may require more demands for repair during the product's life time (Alexander et al., 2008; Liu et al., 2012). However, there are only a few studies that focus on the repair properties of CFRTP under the actual damage such as bending damage.

Therefore, the purpose of this study is to investigate the fracture morphology of CFRTP under a four-point bending load and to evaluate how affect the patch bonding to bending characteristics of damaged CFRTP. CFRTP was fabricated from prepreg, which in turn had been made from plain carbon cloth and Polyamide6 (PA6) sheet. The damage of each carbon cloth at different bending strains was investigated. The effect of patch bonding on the mechanical properties of damaged CFRTP was also characterized under a bending load. In order to estimate the flexural modulus of repaired specimens, the CFRTP was modeled on the basis of laminate beam theory, considering the actual damage state of CFRTP.

\section{Experimental}

\subsection{Materials}

Plain weave carbon cross (TORAY, CO6343) and PA6 (TORAY, CM1017) were used as reinforcement material and matrix, respectively. These configuration and mechanical characteristics were described in Tables 1 and 2 . A 0.1 -mm-thick sheet was fabricated from pelletized PA6 by hot pressing. The PA6 pellets were heated at $240{ }^{\circ} \mathrm{C}$ for $1 \mathrm{~min}$, to avoid clefts during the sheet-forming process. The softened PA6 pellets were pressed at $240{ }^{\circ} \mathrm{C}$ under $5 \mathrm{MPa}$ for $3 \mathrm{~min}$. 
Table 1. Configuration of carbon cross (TORAY, CO6343)

\begin{tabular}{ll}
\hline Warp yarn & T300-3000 \\
Fill yarn & T300-3000 \\
Warp ends [Count $/ 25 \mathrm{~mm}]$ & 12.5 \\
Fill picks $[$ Count $/ 25 \mathrm{~mm}]$ & 12.5 \\
Weight $\left[\mathrm{g} / \mathrm{m}^{2}\right]$ & 198 \\
\hline
\end{tabular}

Table 2. Mechanical characteristics of PA6 (TORAY, CM1017)

\begin{tabular}{ll}
\hline Density $\left[\mathrm{kg} / \mathrm{m}^{3}\right]$ & 1130 \\
Tensile strength $[\mathrm{MPa}]$ & 85 \\
Bending strength $[\mathrm{MPa}]$ & 120 \\
Flexural modulus $[\mathrm{GPa}]$ & 3 \\
\hline
\end{tabular}

\subsection{Fabrication Method}

In this study, CFRTP was produced from prepreg by hot pressing. In order to fabricate prepreg, carbon cloth and $0.1 \mathrm{~mm}$-thick sheets of PA6 were plied and heated for $1 \mathrm{~min}$ at $240{ }^{\circ} \mathrm{C}$ to re-melt the PA6 sheets. Then, these plies were hot pressed at $240^{\circ} \mathrm{C}$ under $5 \mathrm{MPa}$ for $3 \mathrm{~min}$. A 10-ply prepreg laminate was prepared and stacked in laminate configuration $\left[\left(0^{\circ}-90^{\circ}\right) / \pm 45^{\circ} /\left(0^{\circ}-90^{\circ}\right) / \pm 45^{\circ} /\left(0^{\circ}-90^{\circ}\right)\right]_{\mathrm{s}}$. The vacuum bag molding technique was employed to fabricate $2.5-\mathrm{mm}$-thick of CFRTP from these plies. The fiber volume fraction of the fabricated CFRTP was measured by eliminate the PA6 by heating and it result was about $50 \%$. The fabricated CFRTP was cut in parallel with the yarn fiber $\left(0^{\circ}-90^{\circ}\right)$ laminate by a diamond cutter, and, finally, a strip-shaped specimen of size $70 \times 10 \times 2.5 \mathrm{~mm}^{3}$ was prepared.

\subsection{Bending Test}

The four-point bending test was conducted by using a universal testing machine model SHIMADZU EZ-L (according to JIS K 7074). The crosshead speed, upper span length, and lower span length of the bending test were set at $5 \mathrm{~mm} / \mathrm{min}, 17 \mathrm{~mm}$, and $51 \mathrm{~mm}$, respectively. Bending strain and stress were simply calculated by following equations:

$$
\begin{gathered}
\sigma_{B}=\frac{F L}{w t^{2}} \\
\varepsilon_{B}=\frac{470 \delta t}{L^{2}}
\end{gathered}
$$

Here, $F, \delta, L, w$ and $t$ denote applied bending load, deflection, span, width of specimen and thickness of specimen, respectively. At least four specimens were tested to investigate the bending properties.

\subsection{Repair Method}

In order to investigate the change in the bending characteristics by patch bonding, two types of pre-damaged specimens were prepared, in which the applied bending strain was $2.0 \%$ and $2.5 \%$, respectively. In this study, a patch of size $10 \times 30 \mathrm{~mm}^{2}$ was cut from $0^{\circ}-90^{\circ}$ prepreg. The patch was put on the surface of the specimen and, subsequently, both parts were hot pressed at $240^{\circ} \mathrm{C}$, under $2.5 \mathrm{MPa}$ for 3 min to re-melt PA6 and bond together patch and specimen. Considering the actual situation of the repair, the initial size of the specimen was used to calculate the bending properties of the repaired one.

\section{Results and Discussion}

\subsection{Bending Test Results of Virgin Specimen and the Side View of Specimen}

Figure 1 shows the corresponding stress-strain (S-S) diagram during the four-point bending test and the side views of the specimen at different bending strains. Local delamination appeared first at $2.0 \%$ of the applied bending strain. When a bending strain of $2.5 \%$ was applied, fiber structure damage due to local buckling was observed at the compression side of the specimen. In order to investigate the damage of each carbon cloth at different bending strains, six specimens were prepared in which the applied bending strain was varied in steps of 
$0.1 \%$ from $2.0 \%$ to $2.5 \%$. These specimens were heated at $400{ }^{\circ} \mathrm{C}$ for $120 \mathrm{~min}$ to extract the carbon cloths. The damage of each layer at different bending strains is shown in Figure 2. When $2.0 \%$ bending strain was applied, failure of the outer laminate of $0^{\circ}-90^{\circ}$ cloth at the compression side was confirmed. Using the incremental increase of the bending strain, it was found that failure of the carbon cloth initiated from the outer layer at the compression side and propagated up to the third layer of the $0^{\circ}-90^{\circ}$ cloth. When the bending strain reached $2.5 \%$, failure of the carbon cloth was observed not only at the compression side, but also at the tension side. Therefore, in this study, the damage state of the specimens was divided into two classes: moderately damaged (bending strain $\left.\varepsilon_{b}=2.0 \%\right)$ and severely damaged $\left(\varepsilon_{b}=2.5 \%\right)$.

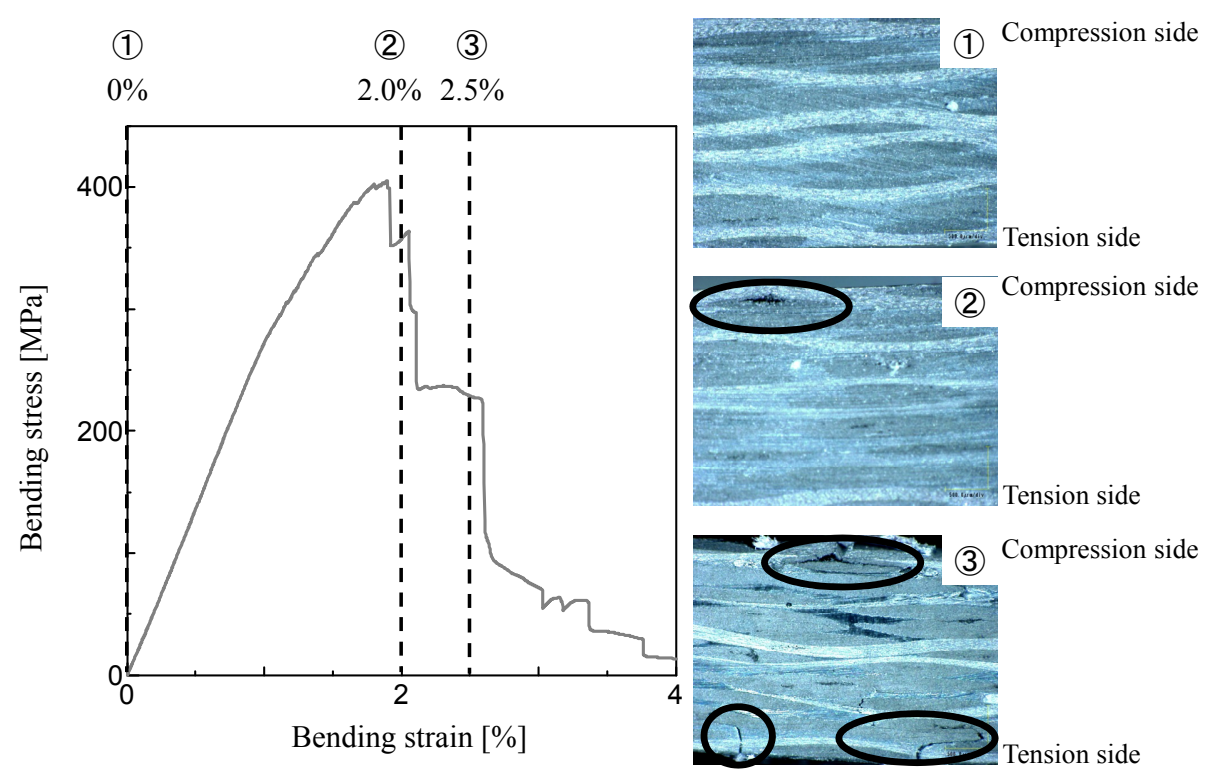

Figure 1. Typical stress-strain (S-S) diagram and side views of the specimen

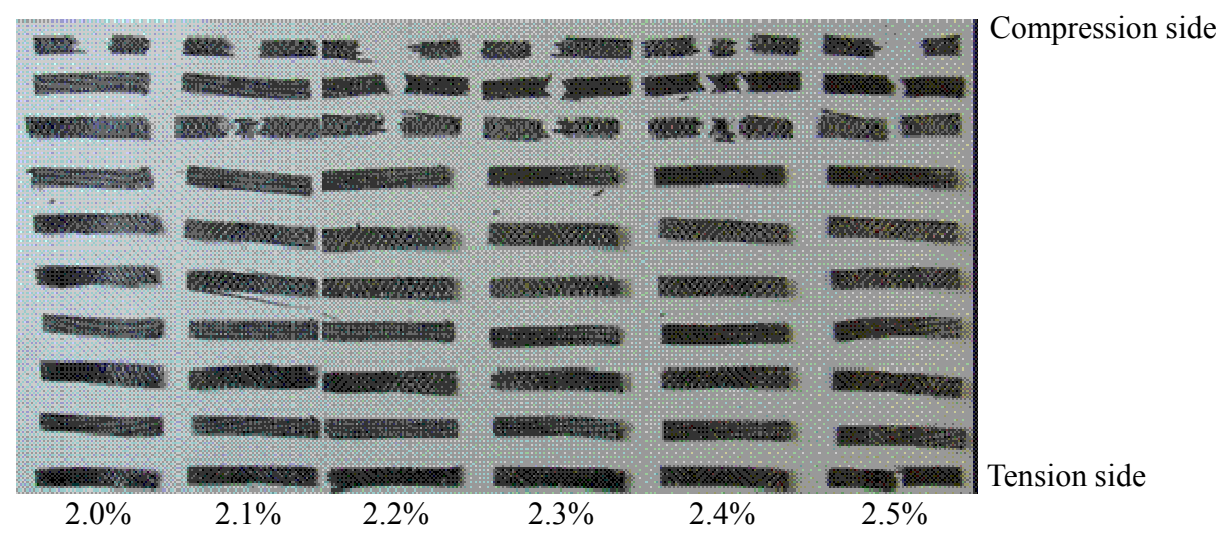

Figure 2. Damage state of each layer at different bending strains

\subsection{Test Results of the Repaired Specimens}

In this study, two types of predamaged specimens ("moderately" damaged and "severely" damaged) were prepared to investigate the effect of patch bonding on its bending characteristics. Figure 3 shows the bending S-S diagrams of virgin, predamaged, and repaired (one patch bonded at the compression side) specimens, respectively. The test results show that the bending characteristics of the predamaged specimens were degraded in comparison of the virgin samples. A recovery of the bending characteristics by patch bonding is also confirmed. To discuss the effect of repair by patch bonding, the normalized bending strength and the normalized 
flexural modulus are introduced by the following definitions:

$$
\begin{gathered}
\sigma_{n}=\frac{\sigma_{B}}{\sigma_{B l}} \\
E_{n}=\frac{E_{B}}{E_{B l}}
\end{gathered}
$$

Here, $\sigma_{n}, \sigma_{B}$, and $\sigma_{B I}$ denote normalized bending strength, bending strength of the repaired specimen, and bending strength of the virgin specimen, respectively. $E_{n}, E_{B}$, and $E_{B I}$ denote normalized flexural modulus, flexural modulus of the repaired specimen, and flexural modulus of the virgin specimen, respectively.

In this study, the number of patches for repairing a damaged specimen was increased until the normalized bending strength and normalized flexural modulus exceeded 1.0. Figures 4 and 5 show the normalized bending strength and normalized flexural modulus of moderately and severely damaged specimens, respectively, repaired by patch bonding. The test results show that in case of a moderate damage, the bending strength and flexural modulus were recovered to value of the virgin specimen by at least two layers of patch bonding at either tension or compression side. On the other hand, in case of severe damage, at least three layers of patch bonding were required to fully recover the bending strength and flexural modulus. The test results also suggest that for the recovery of the bending characteristics, patch bonding at the compression side is more effective than at the tension side.

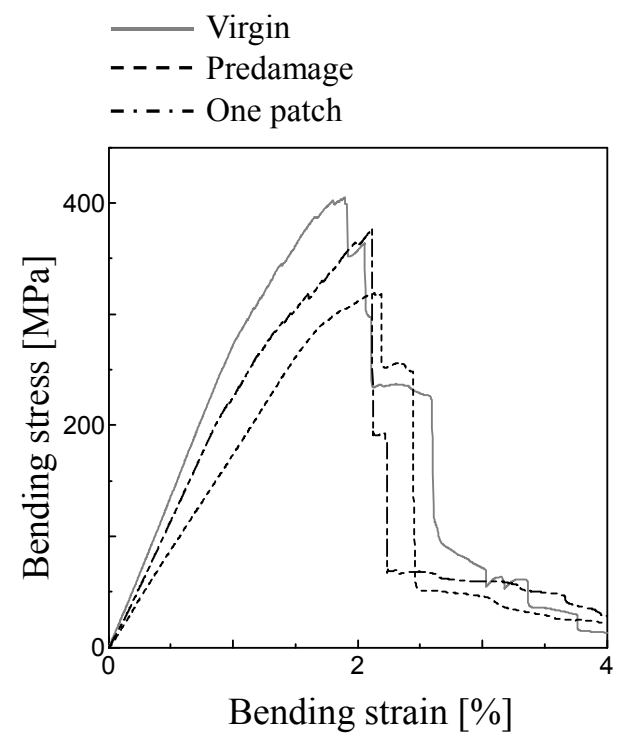

(a) Moderately damaged

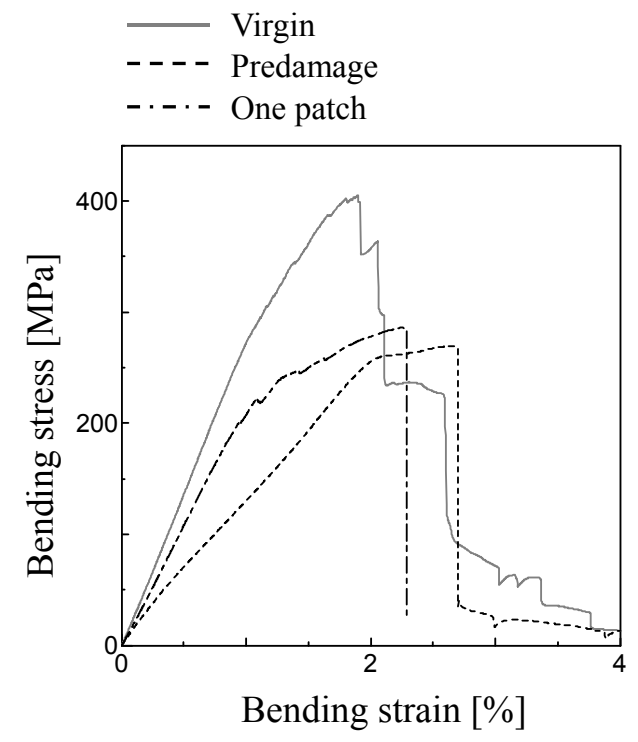

(b) Severely damaged

Figure 3. Typical stress-strain (S-S) diagrams of moderately (left) and severely (right) damaged samples 

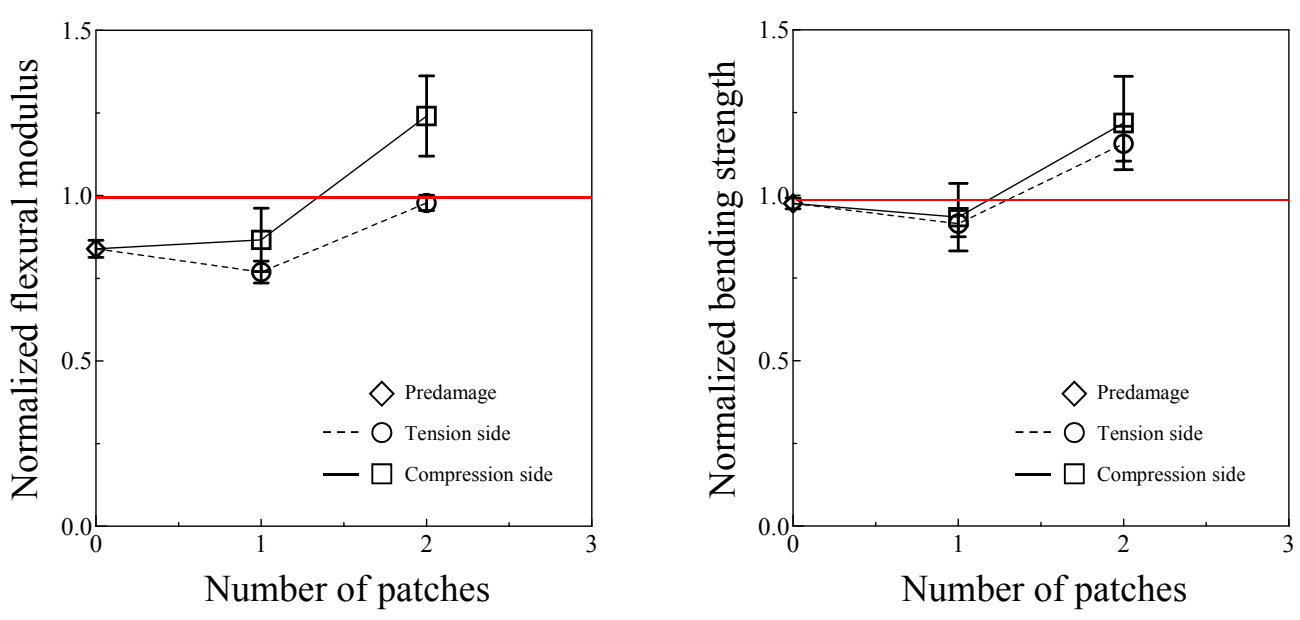

Figure 4. Repair results of moderately damaged specimens $\left(\varepsilon_{\mathrm{b}}=2.0 \%\right)$
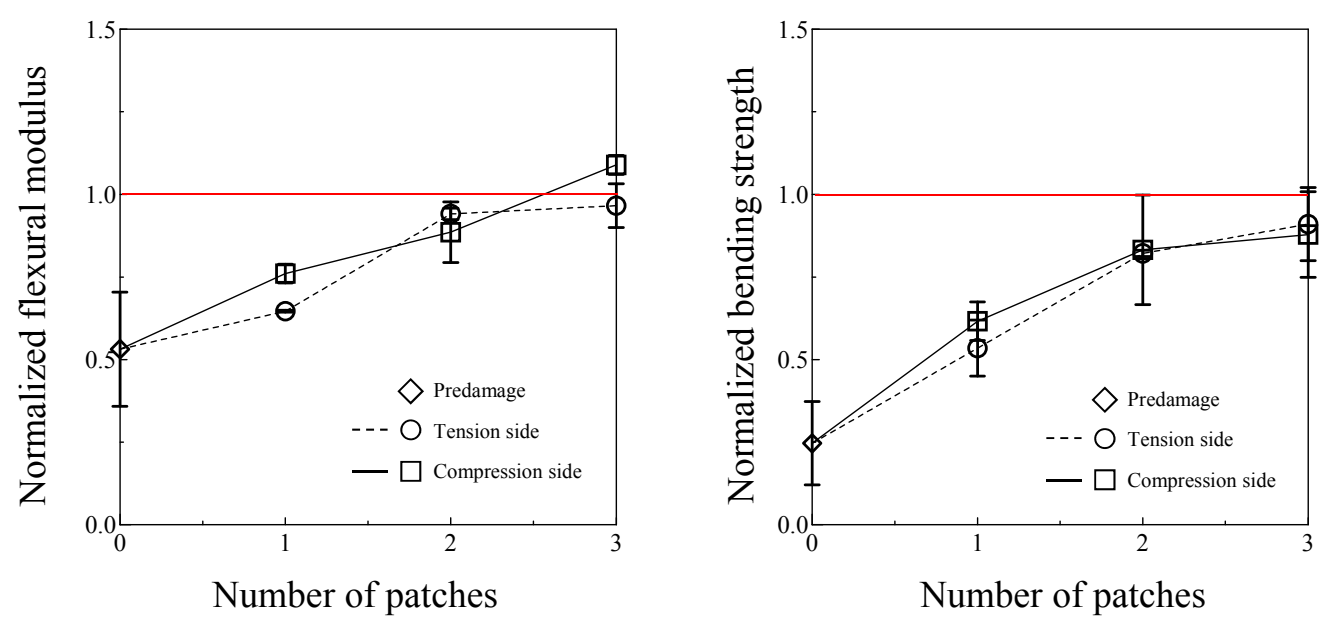

Figure 5. Repair results of severely damaged specimens $\left(\varepsilon_{\mathrm{b}}=2.5 \%\right)$

\subsection{Effect of Bonded Patches onto the Flexural Modulus}

In order to evaluate the flexural modulus of repaired specimens, the CFRTP was modeled on the basis of laminate beam theory. To represent the actual damage state of the CFRTP (discussed in Section 3.1), the flexural modulus of the damaged laminate differs from the undamaged one. Table 3 lists the flexural modulus for the calculation and Figure 6 gives a schematic illustration of the patch-bonded CFRTP. Here, the value of flexural modulus were measured by model specimens, in which laminate configurations were $\left[0^{\circ}-90^{\circ}\right]_{10}$ and $\left[ \pm 45^{\circ}\right]_{10}$, respectively.

To confirm the validity of the model calculations, the bending modulus of severely damaged and repaired specimens was calculated. The actual and estimated values of virgin and repaired samples are shown in Table 4. The calculated results showed a good agreement between the actual and the estimated values. This suggests that the effect of patch bonding on the flexural modulus can simply be estimated by using the laminate beam theory, considering the actual damage state of CFRTP.

The effect of patch bonding on the flexural modulus of a repaired specimen is also discussed. According to the laminate beam theory, the flexural modulus of a repaired specimen is represented by the sum of the bending stiffness of the damaged specimen and the bonded patch:

$$
\sum E_{i} I_{i}=\sum E_{0} I_{0}+\sum E_{p} I_{p}
$$


Here, $\Sigma E_{i} I_{i}, \Sigma E_{o} I_{o}$, and $\Sigma E_{p} I_{p}$ denote the bending stiffness of the repaired specimen, damaged sample, and the bonded patch, respectively. In order to quantitatively discuss the effect of patch bonding on the stiffness of a repaired specimen, the contribution of a patch is parameterized by the ratio of the bending stiffness of the bonded patch to the bending stiffness of the repaired specimen, i.e., $\Sigma E_{p} I_{p} / \Sigma E_{i} I_{i}$. Figure 7 shows the relationship between this stiffness ratio and the number of bonded patch. When the number of patches was increased, the patch contribution to the bending stiffness also increased. Moreover, for the same number of bonded patches, their contribution to the bending stiffness was higher at the compression side than at the tension side.

To explain why the contribution of a patch bonded at the compression side was higher than that at the tension side, the distance between the neutral axis and the outer laminate of a bonded patch was calculated. Figure 8 shows the relationship between the distance from the neutral axis and the number of patches. The distance from the neutral axis to a bonded patch at the compression side is longer than that at the tension side. This result suggests that the moment of inertia per area of the bonded patch at the compression side would be higher than that at the tension side. Therefore, patch bonding at the compression side is more effective than at the tension side. These results also suggest that in order to improve the repairability of patch bonding, the distance between neutral axis and the patch should be longer.

Table 3. Values of the flexural modulus used for the model calculations

\begin{tabular}{lc}
\hline & Flexural modulus [GPa] \\
\hline Non-damaged laminate of $0^{\circ}-90^{\circ}$ & 38.40 \\
Non-damaged laminate of $\pm 45^{\circ}$ & 11.05 \\
Damaged laminate of $0^{\circ}-90^{\circ}$ & 29.62 \\
Damaged laminate of $\pm 45^{\circ}$ & 8.68 \\
\hline
\end{tabular}

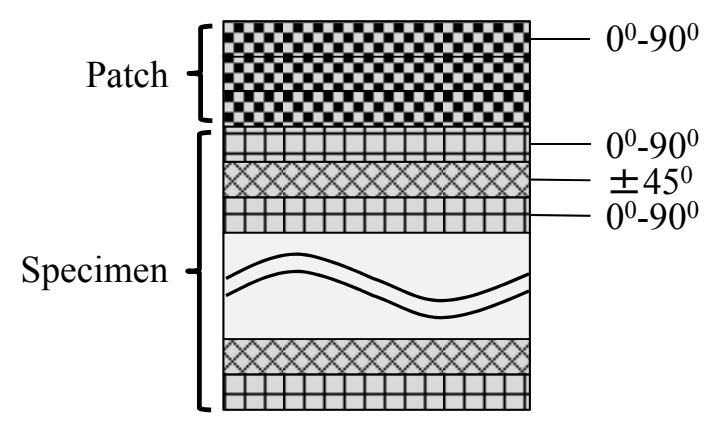

Figure 6. Schematic profile of a repaired sample used for model calculations

Table 4. Actual and theoretical values of the flexural modulus

\begin{tabular}{lcc}
\hline & Actual value [GPa] & Estimated value [GPa] \\
\hline Virgin & $30.4 \pm 0.8$ & 30.0 \\
Three patches at tension side & $27.0 \pm 2.4$ & 27.2 \\
Three patches at compression side & $31.1 \pm 0.7$ & 29.4 \\
\hline
\end{tabular}




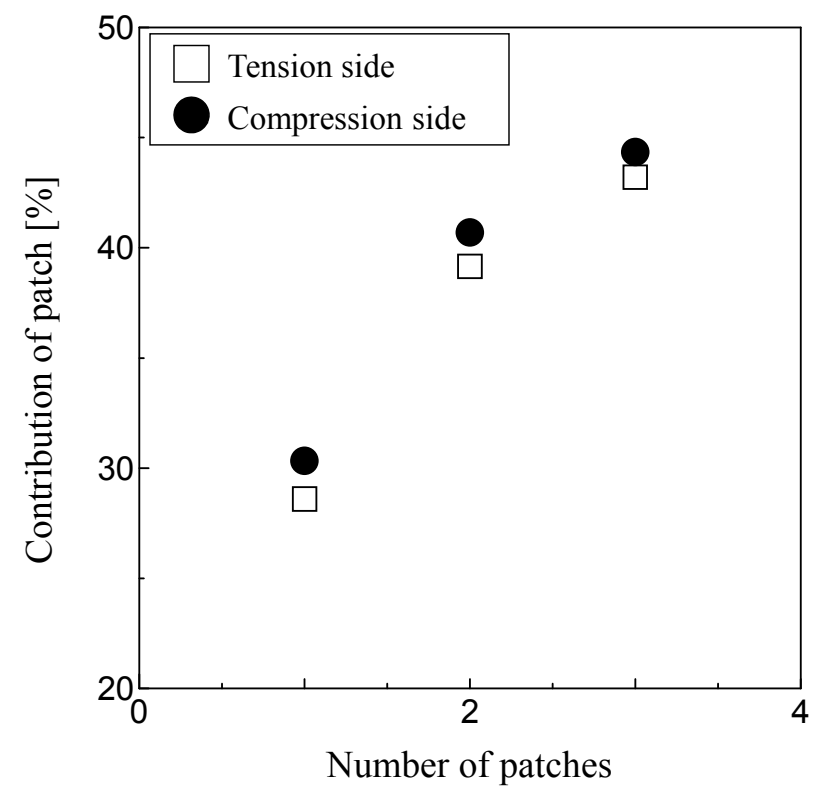

Figure 7. Relationship between the contribution of patch and the number of patches

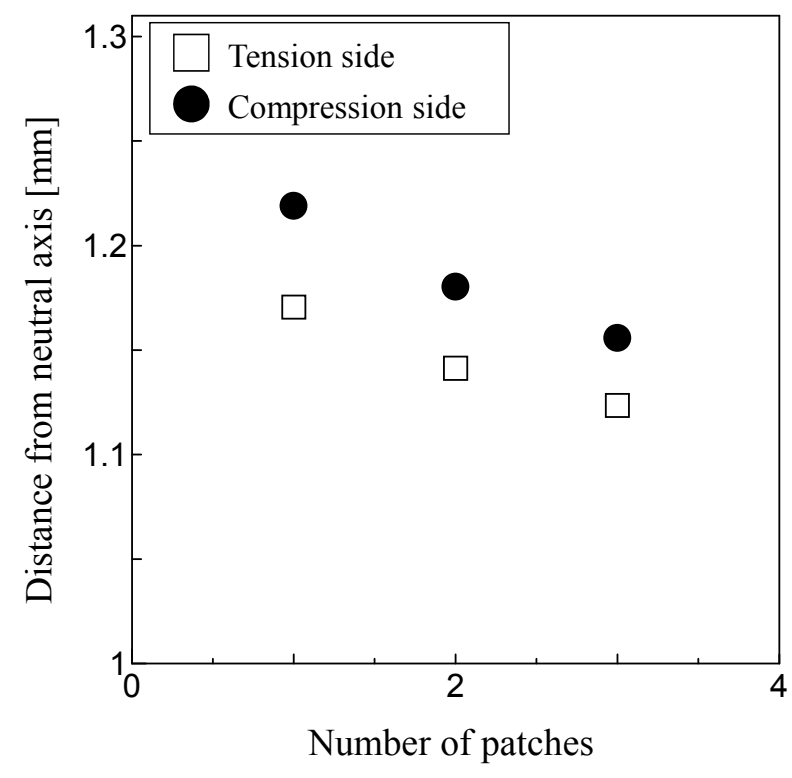

Figure 8. Relationship between the distance from the neutral axis and the number of patches

\section{Conclusions}

(1) When $2.0 \%$ bending strain was applied, failure of the outer laminate of the $0^{\circ}-90^{\circ}$ cloth at the compression side was confirmed. When the bending strain reached $2.5 \%$, failure of the carbon cloth was observed not only at the compression, but also at the tension side.

(2) The damaged specimens could be repaired by the bonding of an appropriate patch layer. Patch bonding at the compression side was more effective than at the tension side.

(3) The effect of patch bonding on the flexural modulus was simply estimated by laminate beam theory, considering the actual damage state of CFRTP.

\section{Acknowledgements}

The authors would like to express thanks to the Japan Society for the Promotion of Science for their generous 
funding during the research and writing of this paper.

\section{References}

Alexander, C., Cercone, L., \& Lockwood, J. (2008). Development of a Carbon-Fiber Composite Repair System for Offshore Risers. In Proceedings of the $27^{\text {th }}$ International Conference on Offshore Mechanics and Arctic Engineering, OMAE2008-57599.

Goto, T., Matsuo, T., Uzawa, K., Ohsawa, I., \& Takahashi, J. (2011). Study on optimal automotive structure made by CFRTP. In Proceedings of the $18^{\text {th }}$ International Conference of Composite Materials, TH32, 1-4.

Liu, X. L., Leong, A. Y. L., Leong, K. H., Falzon, P. J., \& Tan, Y. C. (2012). Heat Transfer Analysis and Cure Modeling of Composite Repairs for Pipelines. In Proceedings of the $8^{\text {th }}$ Asian-Australasian Conference on Composite Materials, O-REP-057.

Matsusaka, N., Takahashi, J., Zushi, H., Osawa, I., \& Uzawa, K. (2005). Evaluation of Recycled CFRTP for Mass Production Applications. In Proceedings of the $9^{\text {th }}$ International SAMPE Symposium, 50-55.

Shinohara, M., Isshiki, S., Fukushima, Y., \& Katayama, T. (2012). Moulding of carbon fiber reinforced polycarbonate (CF/PC) using UD tape. High Performance Structure and Materials, 124, 249-256. http://dx.doi.org/10.2495/HPSM20221

Suzuki, T., \& Takahashi, J. (2005). Prediction of Energy Intensity of Carbon Fiber Reinforced Plastics for Mass-produced Passenger Cars. In Proceedings of the $9^{\text {th }}$ International SAMPE Symposium, 14-19.

Tanaka, K., Yamada, M., Kohashi, N., \& Katayama, T. (2012). High-speed compression moulding of CFRTP/AFRTP hybrid composites using an electromagnetic induction heating system. High Performance Structure and Materials, 112, 141-151. http://dx.doi.org/10.2495/HPSM100141 